\title{
Changes of the Korean Consonant-Vowel Syllabic Recognition Scores According to the Compression Threshold Control of Multi-Channel Hearing Aid
}

\author{
Dajung Yun ${ }^{1}$, Kyoungwon Lee ${ }^{1,2}$ \\ 'Department of Audiology and Speech-Language Pathology, Hallym University of Graduate Studies, Seoul, Korea \\ ${ }^{2}$ HUGS Center for Hearing and Speech Research, Seoul, Korea
}

Received: August 31, 2020
Revised: October 6, 2020
Accepted: October 7, 2020
Correspondence:
Kyoungwon Lee, PhD
Department of Audiology and
Speech-Language Pathology,
Hallym University of Graduate Studies,
427 Yeoksam-ro, Gangnam-gu,
Seoul 06197, Korea
Tel: +82-2-2051-4951
Fax: +82-2-3453-6618
E-mail: leekw@hallym.ac.kr

Purpose: While adjusting the compression threshold (CT) of low and high frequency bands of multi-channel hearing aids in noise, we tried to evaluate any changes in Korean consonant-vowel (CV) syllabic recognition scores, sound quality, and loudness of noise with white noise. Methods: A total of twenty one subjects with hearing loss (mean age of 66.2 years) participated voluntarily. Their pure-tone average was $46.0 \mathrm{~dB} \mathrm{HL}$ and the word recognition score was $72.1 \%$. The CTs of low/ high frequency bands were adjusted to 50/50 dB SPL, 50/65 dB SPL, 65/50 dB SPL and 60/65 dB SPL in multi-channel hearing aids. While presenting white noise to the non-test ear, Korean CV syllables were presented to the test ear to evaluate the recognition scores, clarity of conversational speech, and loudness of noise. The intensity of CV syllables presented to the subject was $50 \mathrm{~dB} \mathrm{HL}$, and the signal-to-noise ratios (SNRs) were $5 \mathrm{~dB}$ and $10 \mathrm{~dB}$. Results: First, when the CT of low/high frequency bands was adjusted to 50/50 dB SPL, the CV syllabic recognition scores were higher compared to $65 / 50 \mathrm{~dB}$ SPL. Second, in the noise environment, the clarity of conversational speech, and loudness of the noise did not have any difference regardless of levels of CT. Conclusion: Based on current findings, the frequency bands setting of $\mathrm{CT}$ in the multi-channel hearing aids might provide changes to recognize Korean speech sounds, which may affect the adjustment of frequency band CT from multichannel hearing aids in the future.

Key Words: Compression threshold, Korean speech, Multi-channel hearing aids, Sound quality, Word recognition score

\section{INTRODUCTION}

감각신경성난청(sensorineural hearing loss)은 달팽이관에서 청각중추에 이르는 청각기관의 기능장애로 인해 발생한다. 특 히 달팽이관 내에 위치한 유모세포의 손상은 청력역치레벨 (hearing threshold level, HTL)을 증가시킴으로 인해 역동범위 (dynamic range)가 감소하고, 조용한 곳 및 잡음하에서 어음인 지도가 저하된다(Dillon, 2012; Gordon-Salant, 2005). 이를 효 과적으로 개선하기 위해서는 비선형 증폭시스템이 각각의 주파 수 대역에서 독립적으로 작동하는 다채널 보청기가 필요하다.

비선형 증폭시스템은 입력에 비해 출력 음압레벨(sound pressure level, SPL)의 증가율이 낮게 나타나는 증폭시스템으로,

(c) This is an Open Access article distributed under the terms of the Creative Commons Attribution Non-Commercial License (https://creativecommons.org/licenses/by-nc/4.0) which permits unrestricted non-commercial use, distribution, and reproduction in any medium, provided the original work is properly cited.
조절할 수 있는 전기음향적 매개변수(parameter)는 입력 SPL 에 대한 이득 즉, 압축역치(compression threshold, CT)와 압축 비율(compression ratio, CR) 그리고 압축시간(attack time)과 해제시간(releas time) 등이 있다. 전기음향적 매개변수의 조절 은 감각신경성난청의 증폭역치(aided threshold)와 역동범위, 신호대잡음비(signal-to-noise ratio, SNR)와 자모음비(consonant-to-vowel ratio, CVR), 보청기의 음질 등에 영향을 준다 (Arehart et al., 2010; Boike \& Souza, 2000; Hornsby \& Ricketts, 2001; Jenstad \& Souza, 2005; Lee, 2014; Souza, 2002; Souza \& Kitch, 2001).

전기음향적 매개변수에서 CT는 선형에서 비선형의 증폭시스 템으로 바뀌는 지점으로 출력 SPL의 증가율이 낮아지기 시작 하는 입력 SPL로 정의하며, CT가 낮을수록 작은 입력 SPL에 대한 이득이 증가하여 난청인의 HTL 및 역동범위의 개선이 가 능하다(Souza, 2002; Lee, 2014). CT와 관련한 연구를 살펴보 
면 20 25 dB SPL의 소리는 송화기의 전기적 잡음으로 CT는 이 강도보다 높아야 하며(Kuk, 1999), $30 \mathrm{~dB}$ SPL 내외의 낮은 $\mathrm{CT}$ 는 감각신경성난청의 역동범위 개선에 효과적이라고 하였다 (Lee \& Kim, 2009). 그러나 Barker \& Dillon(1999)과 Barker et al.(2001)의 연구에서는 중도와 심도의 감각신경성난청은 대 화음레벨인 $65 \mathrm{~dB} \mathrm{SPL}$ 또는 그 이상의 CT를 선호한다고 하였 다. CT에 대한 선행연구를 종합해보면, $50 \mathrm{~dB} \mathrm{SPL}$ 내외의 낮 은 CT는 작은 소리에 대한 이득을 증가하여 HTL을 개선할 수 있으나 보청기의 음질 및 SNR에 나쁜 영향을 줄 수 있다. 그리 고 $65 \mathrm{~dB}$ SPL 전후의 높은 CT에서는 보청기의 음질 및 SNR 의 개선에는 효과적이나 HTL과 CVR의 개선에는 어려움을 줄 수 있다(Kim \& Lee, 2019; Souza, 2002). 그러나 비선형의 단 채널(single channel) 보청기에서는 CT를 모든 주파수 대역에 서 동일하게 설정하기 때문에 주파수 대역별 역동범위, SNR 및 $\mathrm{CVR}$ 의 개선을 동시에 구현할 수는 없다.

다채널(multi-channel) 보청기는 주파수 대역별로 비선형 증 폭시스템이 독립적으로 작동하기 때문에 감각신경성난청의 주 파수 대역별 HTL 및 역동범위의 개선에 효과적이다. 뿐만 아 니라 다채널 보청기는 저주파수 대역의 적절한 압축을 통한 $\mathrm{SNR}$ 의 개선(Keidser \& Grant, 2001; Lee \& Kim, 2009)과 상 향차폐(upward spread of masking) (Danaher \& Pickett, 1975) 를 방지하여 단어인지도의 개선에 효과적이다. 그리고 주파수 대역별로 서로 다른 $\mathrm{CR}$ 을 통한 $\mathrm{CVR}$ 의 개선으로 어음청취력의 향상에 도움을 줄 수 있다(Hansen, 2002). 다채널 보청기와 관 련한 선행연구를 살펴보면, Lunner \& Sundewall-Thorén(2007) 의 연구에서 다채널 보청기를 착용한 감각신경성난청은 청취조 건에 따라 어음인지도가 다르게 나타났으며, Sihn \& Lee (2017)의 연구에서는 전주파수 대역에서 압축시스템이 작동하 는 방식은 저주파수 또는 고주파수 대역에서만 압축시스템이 작동하는 방식에 비해 문장인지도와 명료성이 높게 나타났다. 그리고 $\mathrm{Han}$ et al.(2017)의 연구에서는 중고도 감각신경성난청 은 $61 \mathrm{~dB}$ SPL에 비해 $31 \mathrm{~dB}$ SPL의 낮은 CT에서 배경잡음을 증폭시켜 어음청취를 방해한다고 하였으며, Kim \& Lee(2019) 의 연구에서 다채널 보청기를 착용한 감각신경성난청은 $75 \mathrm{~dB}$ SPL보다 $55 \mathrm{~dB}$ SPL, $65 \mathrm{~dB}$ SPL의 CT에서 단어인지도가 높 게 나타났다.

현재 사용하고 있는 프로그램식 보청기에서는 다채널 보청기 의 주파수반응곡선, $\mathrm{CT}, \mathrm{CR}$ 을 효과적으로 결정하기 위해 보청 기적합공식(hearing aid fitting formula)을 이용하고 있다. 예 를 들어 Figure 6 (Killion \& Fikret-Pasa, 1993), IHAFF (Independent Hearing Aid Fitting Forum) (Cox, 1995), NALNL1 또는 2 (National Acoustic Laboratories - non-linear 1 or 2) (Byrne et al., 2001; Keidser et al., 2011) DSL I/O (de- sired sensation level input/output) (Cornelisse et al., 1995) 등 대부분의 보청기적합공식에서 $\mathrm{CT}$ 와 $\mathrm{CR}$ 은 $\mathrm{HTL}$ 을 기준으로 건청인의 음량증가(loudness growth)를 난청인의 역동범위 내 에 들도록 산출하고 있으며, 보통 대화음레벨의 범위를 고려하 여 CT는 $50 \mathrm{~dB}$ SPL 내외로 낮게 설정하고 있다. 그러나 전주 파수 대역에서의 낮은 CT는 낮은 강도의 입력 SPL에 대한 이 득이 증가하여 SNR의 개선이 어려워 단어인지도가 저하될 우 려가 있다. 또한 고주파수 대역에서 $65 \mathrm{~dB} \mathrm{SPL}$ 내외의 높은 $\mathrm{CT}$ 는 CVR을 나쁘게 하여 에너지가 약한 자음의 청취를 어렵 게 하여 어음인지도를 저하시킬 우려가 있을 것으로 보인다.

본 연구에서는 다채널 보청기의 저주파수와 고주파수 대역별 $\mathrm{CT}$ 를 각각 조절하여 $5,10 \mathrm{~dB} \mathrm{SNR}$ 의 백색잡음(white noise) 하에서 감각신경성난청의 자-모(consonant-vowel, CV)음절 인지도, 대화음의 선명도와 잡음 크기에 대한 심리음향적 특성 을 알아보고자 하였다. 본 연구를 통하여 한국어의 인지도 및 음질의 개선을 위해 다채널 보청기의 주파수 대역별 $\mathrm{CT}$ 의 설정 에 도움을 주고자 하였다.

\section{MATERIALS AND METHODS}

\section{연구 대상}

본 연구에서는 육안검사 시 외이도 및 고막형태가 정상소견 을 보이고, 고막운동도 검사에서 $\mathrm{A}$ 형을 나타냈으며, 250 4,000 $\mathrm{Hz}$ 의 옥타브 주파수에서 기골도차(air-bone gap)가 $15 \mathrm{~dB}$ 이 내인 감각신경성난청인을 대상으로 하였다. 대상자는 21 명(남: 13, 여: 8)으로 평균 연령은 66.2세(SD: 18.27)였다. 대상자 중 10 명은 보청기 착용경험이 없었으며, 나머지 대상자의 평균 보 청기 착용기간은 3.2년(범위: 2 5년)이었다. 그리고 순음역치평 균(pure tone average)의 평균은 $46.0 \mathrm{~dB}$ HL (SD: 10.77)이었 으며, 단어인지도의 평균은 $72.1 \%(\mathrm{SD}: 19.47$ )이었다(Figure 1).

\section{연구 장비 및 도구}

대상자의 기도와 골도 HTL과 단어인지도 검사는 청력검사 기 GSI AudioStar Pro (Grason-Stadler, Eden Prairie, MN, USA)와 TDH-39 (Telephonics, Farmingdale, IL, USA) 헤드 폰을 사용하였다. 음원의 제시는 웨이브(wave) 파일 형식의 음 원과 백색잡음을 노트북 컴퓨터(Samsung, Suwon, Korea)에 저장한 후 컴퓨터와 청력검사기를 연결하여 방음실 내의 외부 스피커(2 ohms)를 통해 제시하였다. 음원 강도의 조절은 $\mathrm{Ado}^{-}$ be Audition (version 3.0, San Jose, CA, USA), 실험에 사용한 보청기는 17 채널의 귀걸이형 TST1786-DW (Beltone Group, Ballerup, Denmark)이었다. 보청기의 전기음향적 조절에 사용 한 보청기적합공식은 NAL-NL2였으며, 주파수 대역별 CT는 
Fonix 7000 (Frye Electronics, Inc., Beaverton, OR, USA)에 서 ANSI S3.42 (American National Standards Institute, 1992) 으로 확인하였다. 대화음의 선명도와 잡음의 크기를 평가하기 위한 문장은 한국표준(KS I ISO 8253-3; Korean Agency for Technology and Standards, 2009)의 성인용 문장 3개였으며, 10점의 Likert 척도로 구성한 설문지(Figure 2)를 이용하여 측 정하였다.

\section{음원 제작}

본 연구에서는 No \& Lee(2012)의 연구에 사용한 CV음절로

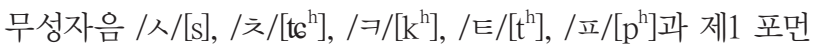
트 주파수가 $300 \mathrm{~Hz}$ 부근인 모음 / / /[a], / //[i]를 조합하여, 총 10 개의 $\mathrm{CV}$ 음절을 사용하였다. $\mathrm{CV}$ 음절의 조절 과정은 첫째, Adobe Audition상에서 평균실효치(root-mean-square)가 동 일하도록 조절하였다. 둘째, 음원을 내장한 컴퓨터와 청력검사 기를 연결한 후 음원을 제시하여 VU meter상에서 음원의 강 도가 $\pm 2 \mathrm{~dB}$ 이내에 들도록 Adobe Audition상에서 추가적으 로 조절하였다. 어음 목록은 총 8 개로 각각의 목록에는 10 개의 $\mathrm{CV}$ 음절을 각 5 개씩, 총 50 개의 $\mathrm{CV}$ 음절 목록으로 구성하였으 며, 각각의 어음 목록에서 $\mathrm{CV}$ 음절을 무작위로 배치하였다. 그 리고 $\mathrm{CV}$ 음절과 함께 제시할 백색잡음은 Adobe Audiotion상

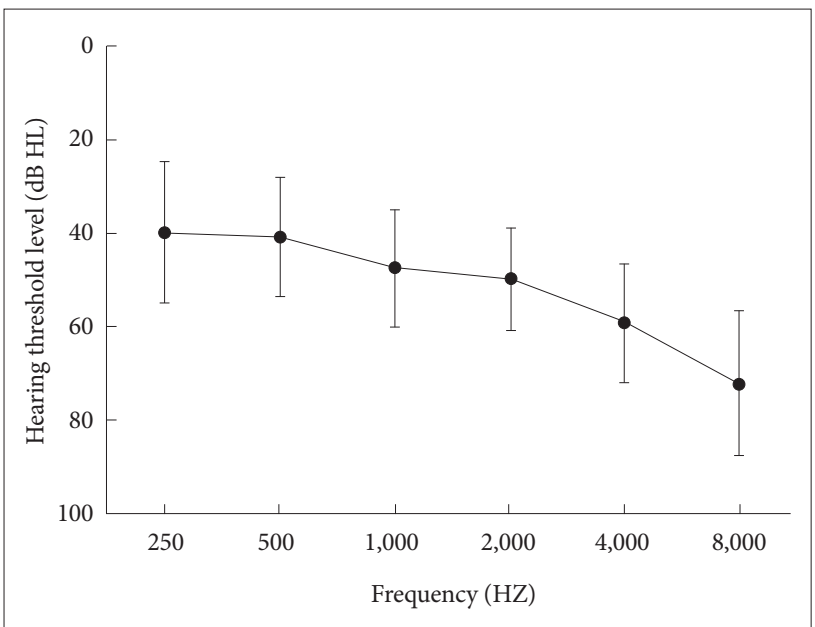

Figure 1. Mean of hearing threshold levels and standard deviations of test ears in each octave frequency.
에서 생성한 다음 평균실효치(root-mean-square)를 기준으로 $5 \mathrm{~dB}, 10 \mathrm{~dB}$ SNR로 조절하였다.

\section{연구 절차}

대상 귀의 선택

$\mathrm{CV}$ 음절을 제시하는 귀는 순음청력평균(pure tone average) 이 같은 경우 단어인지도가 더 높은 귀, 양 측 귀의 청력에 차 이가 나타나는 경우는 순음청력평균이 좋은 귀를 선택하였다. 그리고 비검사 귀는 삽입이어폰(insert phone) 형태의 이어플러 그로 차폐하였다.

\section{보청기의 조절}

$\mathrm{CV}$ 음절과 잡음의 제시 방법은 첫째, 보청기적합 소프트웨어 에 기도 및 골도 HTL을 입력하였다. 둘째, 보청기적합공식 NAL-NL2를 선택하여 자동적합을 실시한 후 1차 전기음향적 조절을 시행하였다. 이때 어음인지도와 음질 변화에 영향을 미 치는 음향피드백 제어시스템(anti-feedback system), 바람소리 감소(wind noise reduction), 어음 강조(speech enhancement), 주파수하강(frequency lowering) 등의 기능을 비활성화 하였 다. 셋째, 주파수 대역별 $\mathrm{CT}$ 즉, 저주파수/고주파수의 CT는 입 력 $50 \mathrm{~dB}$ SPL의 이득을 조절을 통해 50/50, 50/65, 65/50, $65 / 65 \mathrm{~dB}$ SPL로 설정하였다. 넷째, 대상자에게 보통 크기의 말 소리를 들려주고, 심리음향학적 반응을 기준으로 대화음은 편 안하게 그리고 날카롭거나 둔탁하게 들리지 않도록 음량조절 기 및 저주파수 및 고주파수 대역의 이득을 조절하였다. 다섯 째, 성능측정기를 이용하여 주파수 대역별 $\mathrm{CT}$ 를 확인하였으 며, 다시 한 번 대화음을 들려주어 편안하게 들리는지를 확인 하였다. 이때 저주파수와 고주파수를 나누는 교차주파수 (crossover frequency)는 / / /[a], ///[i]의 제1 포먼트 주파수를 고려하여 $1,500 \mathrm{~Hz}$ 부근으로 설정하였다.

압축보청기의 압축시간과 해제시간은 모든 주파수에서 70 $\mathrm{ms}$ 와 $200 \mathrm{~ms}$ 전후로 각각 설정하였다. 그리고 저주파수와 고 주파수의 $\mathrm{CT}$ 를 각각 조절한 후 방음실에서 측정한 증폭역치 (aided threshold)는 Figure 3에 나타내었다.

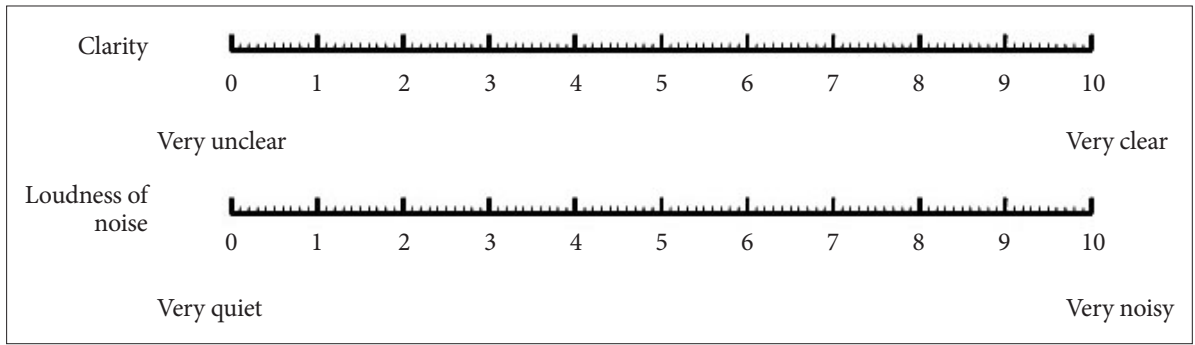




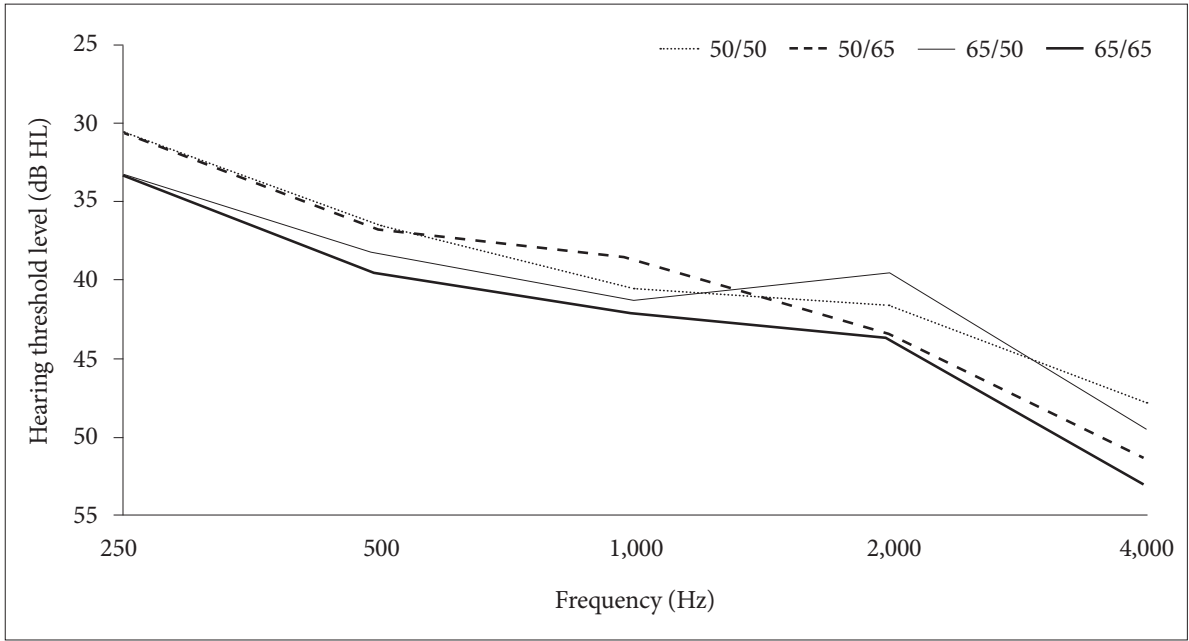

Figure 3. Aided threshold in sound booth after adjusting compression threshold of each low and high frequency band.
Table 1. Results of two-way analysis of variance with repeated measures of consonant-vowel syllabic recognition scores according to the CT of low/high frequency band at 5, $10 \mathrm{~dB}$ SNR

\begin{tabular}{lrrc}
\hline & $\mathrm{F}$ & $\mathrm{df}$, error & \multicolumn{1}{c}{$p$} \\
\hline Main effects & & & \\
$\quad \mathrm{SNR}(5 \mathrm{~dB}, 10 \mathrm{~dB})$ & 14.54 & 1,20 & $0.001^{* *}$ \\
$\quad \mathrm{CT}(50 / 50,50 / 65,65 / 50,65 / 65)$ & 5.22 & 3,60 & $0.003^{* *}$ \\
$\quad$ Interaction & & & \\
$\quad$ SNR $\times$ CT & 1.06 & 3,60 & 0.372 \\
\hline
\end{tabular}

${ }^{* *} p<0.01$. CT: compression threshold, SNR: signal-to-noise ratio

\section{$\mathrm{CV}$ 음절 인지도의 측정 및 음질의 평가}

$\mathrm{CV}$ 음절 인지도 측정 시 외부스피커는 대상자의 뒤통수와 이마를 연결하는 직선을 기준으로 검사 귀의 좌측과 우측의 $45^{\circ}$ 상에 배치하였다. 그리고 $\mathrm{CV}$ 음절은 실험 귀 쪽, 백색잡음은 실험 귀의 반대 방향에서 동시에 제시하였다. $\mathrm{CV}$ 음절의 제시강 도는 $50 \mathrm{~dB} \mathrm{HL}$, 백색잡음의 제시강도는 CT의 조절효과를 잘 반영할 수 있도록 평균 대화음레벨에 비해 작은 $45 \mathrm{~dB} \mathrm{HL}(5$ $\mathrm{dB} \mathrm{SNR})$ 과 $40 \mathrm{~dB} \mathrm{HL}(10 \mathrm{~dB} \mathrm{SNR})$ 이었다. 그리고 각각의 신 호대잡음비에서 50/50, 50/65, 65/50, 65/65 dB SPL의 $\mathrm{CR}$ 를 무작위로 조절한 후 $\mathrm{CV}$ 음절을 제시하였다. $\mathrm{CV}$ 음절 인지도는 대상자가 듣고 따라 말한 50개의 $\mathrm{CV}$ 음절 중 정반응을 백분율 (\%)로 산출하였다. 그리고 CT의 조절에 따른 대화음의 선명도 및 잡음의 크기는 $\mathrm{CT}$ 의 조절에 따른 $\mathrm{CV}$ 음절 인지도를 구한 직후 측정하였다. 문장과 잡음의 제시 방법 및 강도는 $\mathrm{CV}$ 음절 인지도의 측정 방법과 동일하였으며, 선명도 및 잡음의 크기는 대상자가 설문지에 직접 표시하게 하였다.

\section{통계 분석}

본 연구에서는 두 가지의 신호대잡음비(10, $5 \mathrm{~dB} \mathrm{SNR})$ 와 $\mathrm{CT}(50 / 50,50 / 65,65 / 50,65 / 65 \mathrm{~dB} \mathrm{SPL})$ 에 따른 $\mathrm{CV}$ 음절 인지 도와 설문 결과를 분석하였다. 정규분포 검정(Shpiro-Wilk)을
실시한 결과 정규성 만족이 충족된 $\mathrm{CV}$ 음절 인지도는 모수 검 정을, 정규성 만족이 충족되지 않은 설문 결과는 비모수 검정 을 시행하였다. 이에 따라 $\mathrm{CV}$ 음절 인지도는 반복측정 이원분 산분석(two-way analysis of variance with repeated measures) 을 통해 분석한 후 Bonferroni correction method를 이용하여 다중비교 사후분석을 시행하였다. 그리고 설문 결과(명료성과 잡음 크기) 분석에는 프리드만 비모수 검정(Friedman test)을 사용하였다. 모든 분석에서는 양측검정을 실시하였고, 유의 수 준 0.05 를 기준으로 통계적 유의성을 확인하였다. 본 연구의 통 계분석에 사용한 소프트웨어는 SPSS (version 25.0, IBM Corp., Armonk, NY, USA)이었다.

\section{RESULTS}

\section{$\mathrm{CV}$ 음절 인지도}

잡음환경 $5 \mathrm{~dB}$ 와 $10 \mathrm{~dB} \mathrm{SNR에서} \mathrm{저주파수/고주파수의} \mathrm{CT}$ $50 / 50,50 / 65,65 / 50,65 / 65 \mathrm{~dB}$ SPL에 따른 CV음절 인지도의 차이를 분석하였다(Table 1). 분석 결과 잡음환경 $[\mathrm{F}(1,20)=$ $14.54, p<0.01]$ 과 $\mathrm{CT}[\mathrm{F}(3,60)=5.22, p<0.01]$ 에 따른 차이 가 나타났다. 그러나 SNR과 CT 간에 상호작용은 나타나지 않 았다 $[\mathrm{F}(3,60)=1.06, p>0.05]$.

CT에 따른 CV음절 인지도에서 차이가 나타나 각각의 SNR 에서 사후분석을 실시하였다(Figure 4). 분석 결과 CT $50 / 50$, $50 / 65,65 / 50,65 / 65$ 에 따른 $\mathrm{CV}$ 음절 인지도는 $5 \mathrm{~dB} \mathrm{SNR}$ 에서 는 $59.6 \%, 56.1 \%, 54.4 \%, 58.2 \%$ 로 각각 나타나 CT에 따른 CV 음절 인지도의 차이는 나타나지 않았다 $(p>0.05)$. 그러나 10 $\mathrm{dB}$ SNR에서는 $63.5 \%, 61.9 \%, 56.8 \%, 60.6 \%$ 로 $65 / 50$ 에 비해 $50 / 50$ 의 CT에서 CV음절 인지도가 높게 나타났다 $(p<0.01)$. 
Figure 4. Results of consonant-vowel syllabic recognition scores as a function of compression threshold (CT) of low/ high frequency band in $5 \mathrm{~dB}$ and $10 \mathrm{~dB}$ signal-to-noise ratio (SNR) of white noise. $* p<0.01$.

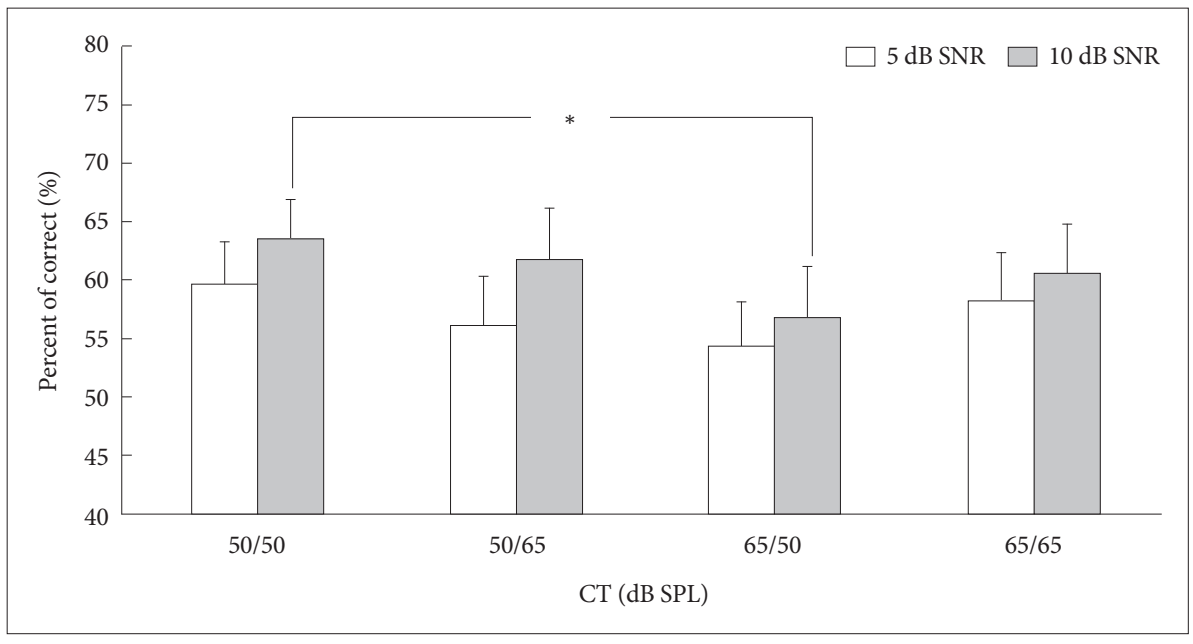

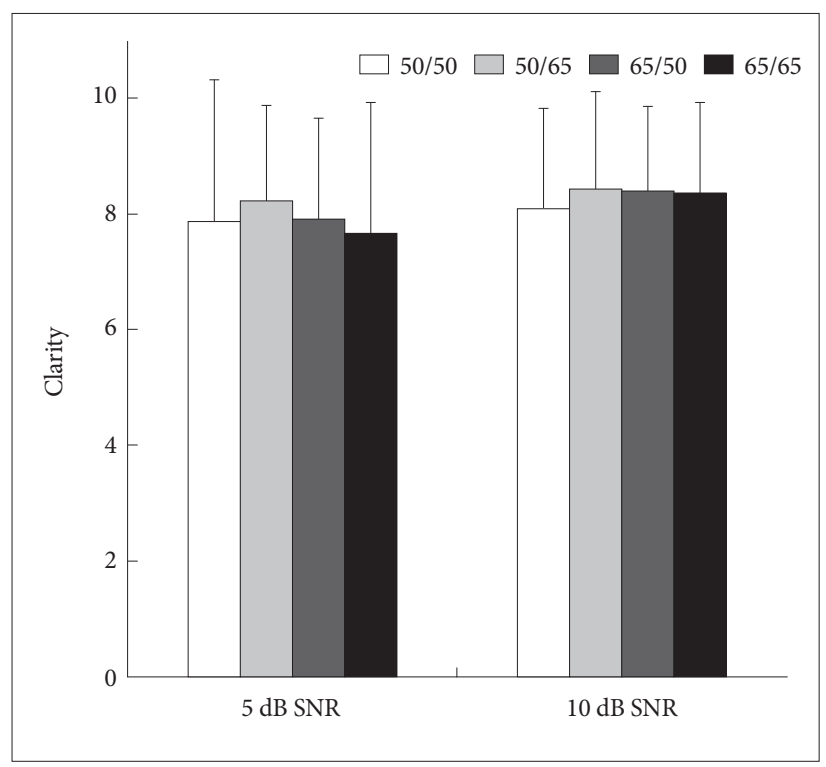

Figure 5. Results of rating scales for sound clarity scores according to adjusting compression threshold of low/high frequency band in noise. SNR: signal-to-noise ratio.

\section{선명도와 잡음의 크기}

$5,10 \mathrm{~dB} \mathrm{SNR}$ 의 잡음환경에서 주파수 대역별 $\mathrm{CT}$ 조절에 따 른 대화음의 선명도와 잡음의 크기를 평가하였다. 저주파수/고 주파수의 CT 50/50, 50/65, 65/50, 65/65 dB SPL에 따른 선명 도는 $5 \mathrm{~dB}$ SNR에서 7.84(SD: 2.45), 8.22(SD: 1.67), 7.85(SD: 1.82), 7.65(SD: 2.26) 그리고 $10 \mathrm{~dB}$ SNR에서 8.09(SD: 1.74), 8.42(SD: 1.69$), 8.37(\mathrm{SD}: 1.47), 8.35(\mathrm{SD}: 1.58)$ 로 각각 나타났다 (Figure 5). 잡음의 크기는 $5 \mathrm{~dB}$ SNR에서 5.05(SD: 3.19), 5.38 (SD: 2.95), 5.43(SD: 2.79), 4.88(SD: 2.97), $10 \mathrm{~dB}$ SNR에서 4.97(SD: 2.98), 4.61(SD: 3.27), 5.19(SD: 3.01), 4.80(SD: 3.20) 으로 각각 나타났다(Figure 6). 프리드만 검정 결과, $5 \mathrm{~dB}$ 와 10 $\mathrm{dB}$ 의 잡음환경에서 선명도 $\left(\chi^{2}=2.60 ; \chi^{2}=0.09\right)$ 와 잡음의 크기

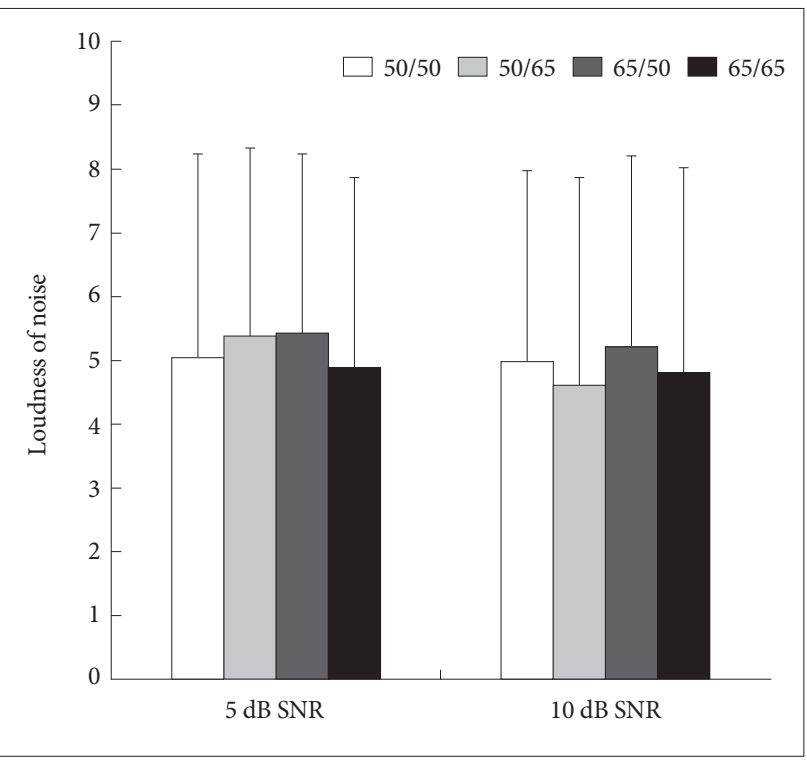

Figure 6. Results of rating scales for loudness of noise according to adjusting compression threshold of low/high frequency band in noise. SNR: signal-to-noise ratio.

$\left(\chi^{2}=3.42 ; \chi^{2}=4.57\right)$ 모두 주파수 대역별 CT의 조절에 유의한 차이는 나타나지 않았다 $(p>0.05)$.

\section{$\mathrm{CV}$ 음절의 오류분석}

백색잡음 환경에서 저주파수/고주파수 CT의 조절에 따른 $\mathrm{CV}$ 음절의 오류분석을 실시하였다. 분석 결과, 초성자음 대치는 $91.01 \%$ 로 나타나 오류의 대부분을 차지했다. 그리고 종성자음 첨가는 $5.16 \%$, 초성자음 생략은 $1.98 \%$ 로 나타났으며, 모음대치 는 $0.55 \%$, 다른 단어는 $0.31 \%$ 로 나타났다(Appendix 1). 가장 많 은 오류를 나타낸 초성자음 대치를 구체적으로 살펴보면, /시s]/ 는 $/$ ᄎ $\left[\mathrm{t}^{\mathrm{h}}\right] /(8.54 \%)$ 와 $/ \mathrm{E}\left[\mathrm{t}^{\mathrm{h}}\right] /(5.90 \%), /$ 之 $\left[\mathrm{t}^{\mathrm{h}}\right] /$ 는 / 시 $[\mathrm{S}] /(9.91 \%)$ 와 $/ E\left[\mathrm{t}^{\mathrm{h}}\right] /(2.64 \%), / \exists\left[\mathrm{k}^{\mathrm{h}}\right] /$ 는 $/ E\left[\mathrm{t}^{\mathrm{h}}\right] /(8.42 \%)$ 와 /ᄎ $\left[\mathrm{tg}^{\mathrm{h}}\right] /(1.92 \%)$, 


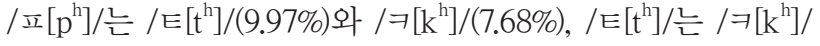
(11.92\%)와 $/$ 표 $\left[\mathrm{p}^{\mathrm{h}}\right] /(2.38 \%)$ 로 대치하였다(Appendix 2).

\section{DISCUSSIONS}

본 연구에서는 다채널 보청기의 저주파수와 고주파수 대역 별 $\mathrm{CT}$ 를 조절했을 때, $5 \mathrm{~dB}$ 와 $10 \mathrm{~dB} \mathrm{SNR}$ 의 백색잡음하에서 $\mathrm{CV}$ 음절 인지도, 대화음의 선명도 및 잡음의 크기에 차이가 나 타나는지를 확인하여 감각신경성난청의 한국어음 인지에 효과 적인 $\mathrm{CT}$ 를 알아보고자 하였다.

본 연구에서 $5 \mathrm{~dB}, 10 \mathrm{~dB} \mathrm{SNR}$ 의 백색잡음하에서 주파수 대 역별 CT를 조절했을 때, $10 \mathrm{~dB} \mathrm{SNR}$ 에 비해 $5 \mathrm{~dB}$ SNR에서 더 낮은 $\mathrm{CV}$ 음절 인지도가 나타나서 잡음이 증가할수록 어음의 인지도가 나빠지는 것으로 나타났다. 다채널 보청기의 SNR에 따른 한국어음의 인지도 연구에서 Park \& Lee(2015)는 CR이 1:1, 2:1, 3:1일 때, SNR이 낮아질수록 단어인지도가 낮게 나타 난다고 보고하였으며, Jeong \& Lee(2018)와 Kim \& Lee(2019) 의 연구에서도 무의미음절 및 초성자음의 인지도는 조용한 환 경에 비해 잡음환경에서 낮게 나타나 본 연구와 일치성을 나타 냈다.

$10 \mathrm{~dB}$ SNR의 백색잡음하에서 저/고주파수 대역별 CT를 조 절했을 때, $\mathrm{CT} 65 / 50 \mathrm{~dB}$ SPL은 50/50 dB SPL에 비해서 더 낮 은 CV음절 인지도가 나타났다. Kim \& Lee(2019)는 다채널 보 청기의 $\mathrm{CT}$ 를 모든 주파수에서 조절했을 때, 잡음하에서의 초 성자음 인지도는 $75 \mathrm{~dB}$ SPL에 비해 $55 \mathrm{~dB}$ 및 $65 \mathrm{~dB} \mathrm{SPL}$ 의 낮 은 CT에서 높게 나타났다. 그리고 Barker \& Dillon(1999)과 Barker et al.(2001)의 연구에서는 낮은 CT가 어음인지도를 개 선시켜 주지만 동시에 잡음도 함께 증폭하여, 어음인지도에 어 려움을 준다고 하였다. Souza(2002)의 연구에서는 낮은 CT와 높은 $\mathrm{CR}$ 이 어음청취력을 개선할 수 있지만 잡음도 함께 증폭 하여 어음의 인지를 방해하며, 높은 $\mathrm{CT}$ 와 낮은 $\mathrm{CR}$ 은 어음청취 력 개선은 어려우나 잡음의 크기가 줄어들며, 음질을 개선할 수 있다고 하였다. 이를 종합해 보면 저/고주파수 대역의 65/50 $\mathrm{dB}$ SPL의 CT에서 저주파수 대역의 높은 CT (65 dB SPL)는 잡음의 증폭을 억제할 수 있지만 한국어의 대역중요함수가 저 주파수 대역에서 높게 나타난다는 보고(Jin et al., 2015; Lee \& Kim, 2012)가 있었듯이 높은 CT가 한국어음의 인지에 영향을 준 것으로 보인다. 또한 Lee et al.(2005)은 한국어 음소의 주파수 특성의 연구에서 폐쇄음, 마찰음, 파찰음은 후행하는 모음 ///[i] 에 의해 자음의 평균 주파수가 높게 따르게 나타난다고 하였 다. 본 연구에서도 무성자음에 모음///[a]와 ///[i]를 결합한 CV 음절을 사용하였기 때문에 $\mathrm{CV}$ 음절 인지도에 영향을 준 것으로 보인다.
본 연구에서의 주파수 대역별 $\mathrm{CT}$ 의 조절에 따른 $\mathrm{CV}$ 음절 인 지도의 오류를 살펴보면 초성자음대치가 가장 높게 나타났다. 구체적으로 살펴보면 / ㅅ/[s] 는 / ㅊ/[th $\left.{ }^{\mathrm{h}}\right]$ 와 / $\mathrm{E} /\left[\mathrm{t}^{\mathrm{h}}\right]$, /ㅊ/[ $\left[\mathrm{t}^{\mathrm{h}}\right]$ 는 / ㅅ/

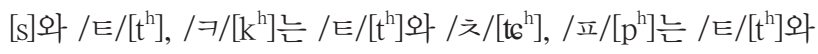

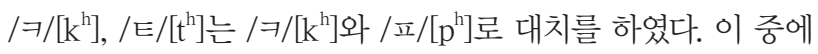
서 가장 많이 나타난 오류를 살펴보면 / 시 [s]와 / ㅊ/[tth]를 서로

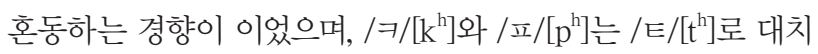
하는 경향이 나타났다. Jeong \& Lee(2018)의 연구에서는 해제 시간 조절에 따른 한국어 $\mathrm{CV}$ 음절 인지도에서 $\left[\mathrm{s}^{\mathrm{h}} \mathrm{a}\right]$ 는 $\left[\mathrm{tc}^{\mathrm{h}} \mathrm{a}\right]$ 와

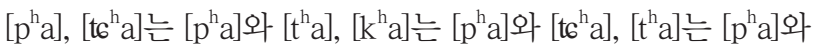
$\left[\mathrm{tc}^{\mathrm{h}} \mathrm{a}\right],\left[\mathrm{p}^{\mathrm{h}} \mathrm{a}\right]$ 는 $\left[\mathrm{tg}^{\mathrm{h}} \mathrm{a}\right]$ 와 $\left[\mathrm{t}^{\mathrm{h}} \mathrm{a}\right]$ 로 초성자음을 대치하는 결과가 나타 났으며 본 연구와는 조금 다른 오류의 형태를 나타냈다. CT와 해제시간을 조절했을 때 CVR이 개선되면 SNR이 저하되는 공 통점이 있지만 본 연구에서는 모음 / / / [a]와 제 2 포먼트 주파수 가 $2,500 \mathrm{~Hz}$ 부근인 / //ii]를 사용하였기 때문에 Jeong \& Lee (2018)의 연구와 차이가 나타난 것으로 생각한다.

그리고 본 연구의 결과에서는 잡음하에서 한국어 문장의 선 명도 및 잡음의 크기는 주파수 대역별 CT의 조절에 따른 차이 가 나타나지 않았다. 이는 모든 주파수 대역의 CT를 동일하게 조절하여 잡음의 크기를 비교했을 때, $55 \mathrm{~dB} \mathrm{SPL}$ 의 낮은 CT 에서 잡음을 더 크게 인지했다는 Kim \& Lee(2019)의 연구와 는 차이를 나타냈다. 본 연구에서는 저주파수 및 고주파수 대 역별 CT를 각각 조절했기 때문에 명확한 잡음의 크기가 나타 나지 않은 것으로 볼 수 있다.

본 연구에서는 대상자의 순응(acclimatization) 기간은 고려하 지 않고 $\mathrm{CT}$ 조절 직후 $\mathrm{CV}$ 음절의 인지도, 한국어 문장의 음질 및 잡음의 크기를 평가한 것은 한계점으로 볼 수 있다. 따라서 향후에는 순응 기간을 고려하고 대상자의 HTL 또는 역동범위, 단어인지도, 보청기의 형태 등을 고려한 연구가 필요할 것이다.

본 연구에서 감각신경성 난청인이 다채널 보청기를 착용한 후 저/고주파수 대역의 CT를 50/50 dB SPL로 조절했을 CV음 절 인지도가 높게 나타났다. 본 연구의 결과, 다채널 보청기에서 CT의 주파수 대역별 설정은 한국어음의 인지도에 영향을 주 는 것으로 나타서 향후 다채널 보청기의 주파수 대역별 CT의 설정에 영향을 줄 수 있을 것이다.

중심 단어 : 압축역치·한국어음·다채널 보청기·음질·단어인 지도.

\section{Ethical Statement}

This study was approved by the Institutional Review Board of Hallym University of Graduate Studies (IRB \#HUGSAUD261734).

\section{Acknowledgments}

Thanks to the Resound Korea for providing multi-channel hearing aids. 


\section{Declaration of Conflicting Interests}

There are no conflict of interests.

\section{Funding}

This research was completed while being supported by National Research Foundation of Korea (2018R1A2B6001986).

\section{Author Contributions}

K.L. designed experimental procedures. D.Y. collected and analyzed data. D.Y. and K.L. wrote the paper, analyzed each data and discussed the results together.

\section{ORCID iDs}

Dajung Yun

Kyoungwon Lee

https://orcid.org/0000-0002-2044-6486

https://orcid.org/0000-0002-1297-6436

\section{REFERENCES}

American National Standards Institute. (1992). Testing Hearing Aids with a Broad-Band Noise Signal (ANSI S3.42-1992). New York, NY: Acoustical Society of America.

Arehart, K. H., Kates, J. M., \& Anderson, M. C. (2010). Effects of noise, nonlinear processing, and linear filtering on perceived speech quality. Ear and Hearing, 31(3), 420-436.

Barker, C. \& Dillon, H. (1999). Client preferences for compression threshold in single-channel wide dynamic range compression hearing aids. Ear and Hearing, 20(2), 127-139.

Barker, C., Dillon, H., \& Newall, P. (2001). Fitting low ratio compression to people with severe and profound hearing losses. Ear and Hearing, 22(2), 130-141.

Boike, K. T. \& Souza, P. E. (2000). Effect of compression ratio on speech recognition and speech-quality ratings with wide dynamic range compression amplification. Journal of Speech, Language, and Hearing Research, 43(2), 456-468.

Byrne, D., Dillon, H., Ching, T., Katsch, R., \& Keidser, G. (2001). NAL-NL1 procedure for fitting nonlinear hearing aids: Characteristics and comparisons with other procedures. Journal of the American Academy of Audiology, 12(1), 37-51.

Cornelisse, L. E., Seewald, R. C., \& Jamieson, D. G. (1995). The input/output formula: A theoretical approach to the fitting of personal amplification devices. The Journal of the Acoustical Society of America, 97(3), 18541864.

Cox, R. M. (1995). Using loudness data for hearing aid selection: The IHAFF approach. The Hearing Journal, 48(2), 10, 39-44.

Danaher, E. M. \& Pickett, J. M. (1975). Some masking effects produced by low-frequency vowel formants in persons with sensorineural hearing loss. Journal of Speech and Hearing Research, 18(2), 261-271.

Dillon, H. (2012). Hearing Aids. (2nd ed.). Sydney: Boomerang Press.

Gordon-Salant S. (2005). Hearing loss and aging: New research findings and clinical implications. Journal of Rehabilitation Research and Development, 42(4 Suppl 2), 9-24.

Han, W., Lee, J., Kim, J., Lee, K., \& Kim, D. (2017). Preferred compression threshold and release time in quiet and noisy conditions for elderly Korean hearing aid users. Journal of Audiology and Otology, 21(3), 133139.

Hansen M. (2002). Effects of multi-channel compression time constants on subjectively perceived sound quality and speech intelligibility. Ear and
Hearing, 23(4), 369-380.

Hornsby, B. W. \& Ricketts, T. A. (2001). The effects of compression ratio, signal-to-noise ratio, and level on speech recognition in normal-hearing listeners. The Journal of the Acoustical Society of America, 109(6), 2964-2973.

Jenstad, L. M. \& Souza, P. E. (2005). Quantifying the effect of compression hearing aid release time on speech acoustics and intelligibility. Journal of Speech, Language, and Hearing Research, 48(3), 651-667.

Jeong, J. \& Lee, K. (2018). Changes of non-sense syllabic word scores and preferences as a function of release time on multi-channel hearing aids. Audiology and Speech Research, 14(4), 250-258.

Jin, I. K., Kates, J. M., Lee, K., \& Arehart, K. H. (2015). Derivations of the band-importance function: A cross-procedure comparison. The Journal of the Acoustical Society of America, 138(2), 938-941.

Keidser, G., Dillon, H., Flax, M., Ching, T., \& Brewer, S. (2011). The NALNL2 prescription procedure. Audiology Research, 1(1), e24.

Keidser, G. \& Grant, F. (2001). The preferred number of channels (one, two, or four) in NAL-NL1 prescribed wide dynamic range compression (WDRC) devices. Ear and Hearing, 22(6), 516-527.

Killion, M. C. \& Fikret-Pasa, S. (1993). The 3 types of sensorineural hearing loss: Loudness and intelligibility considerations. The Hearing Journal, 46(11), 31-36.

Kim, S. \& Lee, K. (2019). Changes of consonant recognition and sound quality as a function of compression threshold on multi-channel hearing aids. Audiology and Speech Research, 15(1), 23-29.

Korean Agency for Technology and Standards. (2009). Acoustics-Audiometric Test Methods-Part 3: Speech Audiometry (KS I ISO 8253-3). Gwacheon: Korean Agency for Technology and Standards.

Kuk, F. (1999). Optimizing compression: The advantages of a low compression threshold. High Performance Hearing Solutions, 3, 44-47.

Lee, J. H., Jang H. S., \& Chung H. J. (2005). A study on frequency characteristics of Korean phonemes. Audiology, 1(1), 59-66.

Lee, K. W. (2014). Changes of dynamic range, signal-to-noise ratio, and consonant-to-vowel ratio by electroacoustic adjustment and fitting in non-linear hearing aids. Audiology, 10(3), 190-197.

Lee, K. W. \& Kim, J. S. (2009). Review in hearing aid prescription methods and its considerations in Korean studies. Audiology, 5(1), 6-12.

Lee, K. W. \& Kim, J. S. (2012). The study of frequency importance function of the Korean monosyllabic words. Audiology, 8(1), 24-33.

Lunner, T. \& Sundewall-Thorén, E. (2007). Interactions between cognition, compression, and listening conditions: Effects on speech-in-noise performance in a two-channel hearing aid. Journal of the American Academy of Audiology, 18(7), 604-617.

No, B. I. \& Lee, J. H. (2012). A comparison study of monosyllable recognition in listeners with sloping versus flat hearing loss types. Audiology, 8(1), 78-86.

Park, S. Y. \& Lee, K. (2015). Comparisons of the sentence recognition scores and sound qualities as a function of compression ratios. Audiology, 11(4), 292-301.

Shin, S. \& Lee, K. (2017). Comparisons of sentence recognition scores and preferences according to compression types in a multi-channel hearing aid. Audiology and Speech Research, 13(1), 88-94.

Souza, P. E. (2002). Effects of compression on speech acoustics, intelligibility, and sound quality. Trends In Amplification, 6(4), 131-165.

Souza, P. E. \& Kitch, V. (2001). The contribution of amplitude envelope cues to sentence identification in young and aged listeners. Ear and Hearing, 22(2), 112-119. 


\section{APPENDICES}

Appendix 1. The Error Patterns of CV Syllables (\%)

\begin{tabular}{|c|c|c|c|c|c|}
\hline \multicolumn{2}{|c|}{ 초성자음 } & \multirow{2}{*}{$\begin{array}{c}\text { 종성자음 } \\
\text { 첨가 }\end{array}$} & \multirow{2}{*}{$\frac{\text { 모음 }}{\text { 대치 }}$} & \multirow{2}{*}{ 다른 단어 } & \multirow{2}{*}{ 무응답 } \\
\hline 대치 & 생략 & & & & \\
\hline 91.01 & 1.98 & 5.16 & 0.55 & 0.31 & 0.96 \\
\hline
\end{tabular}

Appendix 2. Results of Phoneme Substitutions of CV Syllables According to the Compression Threshold on Frequency Band in 5, 10 dB SNR

\begin{tabular}{|c|c|c|c|c|c|c|c|c|c|}
\hline \multicolumn{10}{|c|}{ 초성자음대치(\%) } \\
\hline \multicolumn{2}{|c|}{ |ᄉ| } & \multicolumn{2}{|c|}{ /玄/ } & \multicolumn{2}{|c|}{ /ヨ/ } & \multicolumn{2}{|c|}{ /피 } & \multicolumn{2}{|c|}{ /E/ } \\
\hline $\bar{\lambda}$ & 8.54 & $\curlywedge$ & 9.91 & E & 8.42 & E & 9.97 & F & 11.92 \\
\hline E & 5.90 & $E$ & 2.64 & $\overline{\bar{\lambda}}$ & 1.92 & $\exists$ & 7.68 & II & 2.38 \\
\hline$\pi$ & 2.18 & $\pi$ & 2.55 & 프 & 1.69 & $\neg$ & 2.01 & $\bar{\lambda}$ & 1.89 \\
\hline II & 2.12 & $\neg$ & 2.26 & $\neg$ & 1.66 & $\forall$ & 1.46 & $\neg$ & 1.32 \\
\hline$\neg$ & 0.86 & $\exists$ & 1.40 & $\curlywedge$ & 0.77 & $\curlywedge$ & 1.00 & $\pi$ & 0.40 \\
\hline$\exists$ & 0.86 & II & 1.32 & $\pi$ & 0.37 & $\overline{\bar{\lambda}}$ & 1.00 & $\curlywedge$ & 0.34 \\
\hline ᄃ & 0.49 & $\bar{\partial}$ & 0.32 & $\bar{\partial}$ & 0.23 & $\pi$ & 0.14 & के & 0.14 \\
\hline क & 0.37 & $\forall$ & 0.23 & $\forall$ & 0.11 & $\bar{\partial}$ & 0.11 & $\sqsubset$ & 0.11 \\
\hline$\forall$ & 0.23 & \llcorner & 0.11 & \llcorner & 0.09 & ᄃ & 0.09 & 口 & 0.03 \\
\hline ㅁ & 0.11 & $\sqsubset$ & 0.06 & $\sqsubset$ & 0.06 & 世 & 0.06 & $\forall$ & 0.03 \\
\hline ᄂ & 0.06 & $\mu$ & 0.03 & ᄅ & 0.03 & $\square$ & 0.03 & & \\
\hline
\end{tabular}

